SHORT REPORT

\title{
A comprehensive "Healthy Schools Programme" to promote school health: the Hong Kong experience in joining the efforts of health and education sectors
}

\author{
A Lee, C Tsang, S H Lee, C Y To
}

J Epidemiol Community Health 2003;57:174-177

Both health and education are linked to economic performance. The success of education depends on good health, and vice versa. Modern education should help young people to determine values, and accept responsibility for their health and social behaviour. The success of health promotion in schools requires the joint efforts of both the health and education sectors. A comprehensive programme is needed to include teachers' training, curriculum development, community participation, changing policies and practices, and research. All these components are needed to build up a successful model of a health promoting school. The "Healthy Schools Programme" in Hong Kong gives a good example of close partnership between the health and education sectors, and moves towards a multidisciplinary approach and active learning towards health promotion.

$\mathrm{H}$ ealth prospects are, at least in part, determined by educational opportunity and achievement, and learning outcomes are often dependent upon health status. Both health and education are linked to the economic performance and social cohesion of modern industrialised society. Modern education should be about more than developing the necessary knowledge and skills required for work and everyday living, it should also help our young people to determine their values. The health education programmes should include providing information, exploring values and attitudes, making health decisions, and acquiring skills to enable behaviour change to take place. Health education programmes should also train people to develop self esteem and self empowerment so that they are enabled to take action about their health.

In broader terms, one can define health education as providing health information, helping people to change their attitude and behaviour towards healthier lifestyles, and empowering people to look after their own health. The World Health Organisation defines the process of enabling people to increase control over, and to improve, their health as "health promotion". Modern school health education should therefore include training in health promotion skills. This means acquiring the knowledge and skills for working with people to promote health in many different situations with a variety of different aims. During a Health Promoting School Conference, Professor Lowell Levin emphasised that the classroom teacher is the key to creating learning opportunities within and beyond the classroom, and to building children's future capacities to grow, be productive, and accept lifelong responsibility for their health and social behaviour. ${ }^{1}$ Therefore schools should be considered as a health promoting setting.

The comprehensive school health education programme can only be successful in promoting school health if partners beyond the health sector, such as education and social services, are actively involved. Schools would be the catalyst for bringing together the various agencies that have an impact upon the health of the community. Most school communities are microcosms of the larger community, providing opportunities for children to develop and practice the skills necessary for supporting a healthy lifestyle. The health educators should be synthesised into the "health promoting school" model, which is guided by a holistic view of health and by the principles of equity and empowerment. ${ }^{2}$

Successful examples from the European Network of Health Promoting Schools (ENHPS) project demonstrated that there was a need to adopt a holistic approach to health that transcends the classic relations and interactions between the health and education sectors. ${ }^{3}$ The main problems encountered were lack of resources and insufficient training opportunities.

\section{MAKING HEALTH PROMOTING SCHOOLS A SUCCESS: A COMPREHENSIVE "HEALTHY SCHOOLS PROGRAMME"}

The success of health promoting schools will depend heavily on teachers' training. However, one study shows that teachers think mainly about school health in terms of curriculum, have little understanding of how community partnership might work, and have little pre-service and in-service training. ${ }^{4}$ Therefore health education and health promotion should be an essential element in teacher training.

In reviewing the case studies of the ENHPS, there are several important areas for teacher training and curriculum development. ${ }^{5}$ There was a strong need for change in the long established traditional approach to school health education, which concentrated on its physical aspects through largely negative messages. It was concluded that the key determinant of the successful and efficient implementation of health and education programmes is the ability of the teachers to understand the basic concepts and communicate their meaning to others. The focus should be based on the interaction of the informal and formal school curriculum, and the practical involvement of new partners in health promoting schools.

The emphasis should also be placed on helping children and young people to develop positive self esteem and personal and social skills. Teachers should be provided with practical advice about conflict resolution. This requires a substantial shift from didactic to much less formal teaching methods, which would create difficulties for some teachers and pupils. In another study, it was also revealed that the less frequently tackled issues in school health were mental health, accident prevention, staff health, and developing links with the wider community. ${ }^{6}$

The education system in Hong Kong has been based on the old English system. Students need to complete an assessment before entry to secondary school and, after five years of study, will sit an open examination similar to the English General Certificate of Education Ordinary Level. Those who perform well will proceed to a two year matriculation course, then sit 
an advanced level examination for entry to university. The system places a very strong emphasis on academic achievement. Health education is taught as part of general knowledge in primary school. In secondary schools, health education is taught by cross-curriculum. The extent of health education and health promotion activities as informal curriculum varies considerably among schools, depending on the priority of the individual school.

School health promotion is a dynamic process requiring continuous monitoring and assessment, and therefore a more comprehensive Healthy Schools Programme is urgently needed to tackle the above mentioned problems. The Healthy Schools Programmes launched by the Chinese University of Hong Kong in collaboration with the three major schools councils* in Hong Kong include the following aspects:

(1) To offer a two year, part time Professional Diploma course in Health Promotion and Health Education to train school related workers.

(2) To publish journals, textbooks, and periodicals on health promotion and health education for school health workers, parents, and students.

(3) To conduct research in health promotion and health education, such as assessments of the health needs of students and public health problems concerning children and adolescents, and evaluation of health education intervention, etc.

(4) To enrich the curriculum of health education in schools, and to organise and participate in local and regional conferences or seminars on health education and health promotion.

(5) To provide consultancy services in health promotion for the school community.

(6) To act as a liaison body, and establish a network of academic and professional staff in health education from universities and other professional institutions or organisations, both local and overseas, to foster health promotion and health education in Hong Kong, Southern China, and the Western Pacific region.

The main emphasis of the programme is improved communication between health services and education staff at all levels, which will facilitate the widespread introduction and development of the health promoting school concept. ${ }^{78}$ The programme has received funding of HK 15 million (about US\$ 1.9 million) from the Quality Education Fund, set up by the Hong Kong Special Administrative Region Government. The diploma course is on the education department's list of training courses to be considered for promotion to teachers. The recognition by the education authority will give a strong signal about the importance of school teachers being involved in school health.

\section{THE OBJECTIVES OF THE TRAINING COURSE}

The diploma course is a two year, part time programme. The content of the course puts strong emphasis on the holistic approach to health, and also practical skills training in the implementation of school health education and promotion programmes. The course will also cover issues such as the changing policies and practices of the school, so that a broad based policy for health covering both pupils and staff can be developed. The course also considers the importance of the integration of school programmes with community resources. These areas have been identified as key components of health promoting schools. ${ }^{29}$ The training course is designed with the aim that, on graduation, participants should have:

*The Hong Kong Subsidized Secondary Schools Council, Subsidized Primary Schools Council, Hong Kong Special Schools Council.
(1) the ability to read and comprehend health related issues

(2) the ability to take preventive measures and preliminary action against health problems encountered by the school children

(3) the ability to find information for basic problem solving in health matters related to school children

(4) the ability to organise health promotion programmes at school

(5) the ability to teach basic concepts in health education

(6) the ability to coordinate health promotion research and curriculum development, and to organise health promotion programmes on territory wide or network basis

Organised education is the most powerful tool available to both protect the welfare of citizens, and to take advantage of the social and economic opportunities to advance health. ${ }^{1}$ Therefore well structured training in health promotion and health education is essential for the school teachers so they can commit to implementing the idea of a health promoting school and take up the challenge of moving away from old style health education to the whole settings approach, and the broad ranging, comprehensive collection of actions. ${ }^{10}$

\section{WHAT ARE THE AREAS TO BE INCLUDED IN A COMPREHENSIVE SCHOOL HEALTH EDUCATION PROGRAMME IN HONG KONG: SCHOOL EDUCATORS' PERSPECTIVE}

Towards the end of module 1 , the course participants take part in a workshop on designing the outlines of a comprehensive school health education programme. The following components are included:

- Understanding of common diseases and the diseases that are a major cause of death in Hong Kong

- Coping with stress and understanding of emotional problems

- Understanding puberty and learning how to cope

- Improve self esteem of students

- Healthy school environment

- Nutrition and health

- Exercise and health

- Counselling for psychological and social problems

- School health services for regular body and dental check ups

- Health promotion for staff

- Parents and community participation in school health

The course participants are asked to work out the strategies for implementation. They adopted a multi-faceted approach involving health sectors, social services, and parents. They have also mobilised the support of their colleagues, and have moved away from formal curriculum to extra-curricular activities with active participation from pupils, teachers, parents, and members of the community.

To develop their practical skills, and to develop and implement health education and health promotion programmes in schools, the course participants will work on a project in groups of 10 or 12 under supervision. This will also improve team work and networking skills. Project topics cover the wide range of important problems experienced by the school children, based on their previous discussions on the comprehensive health education programme. The titles of their projects are as follows:

- Exercise and health

- The influence of the relationship between parents and children on childhood development

- The breakfast menu 


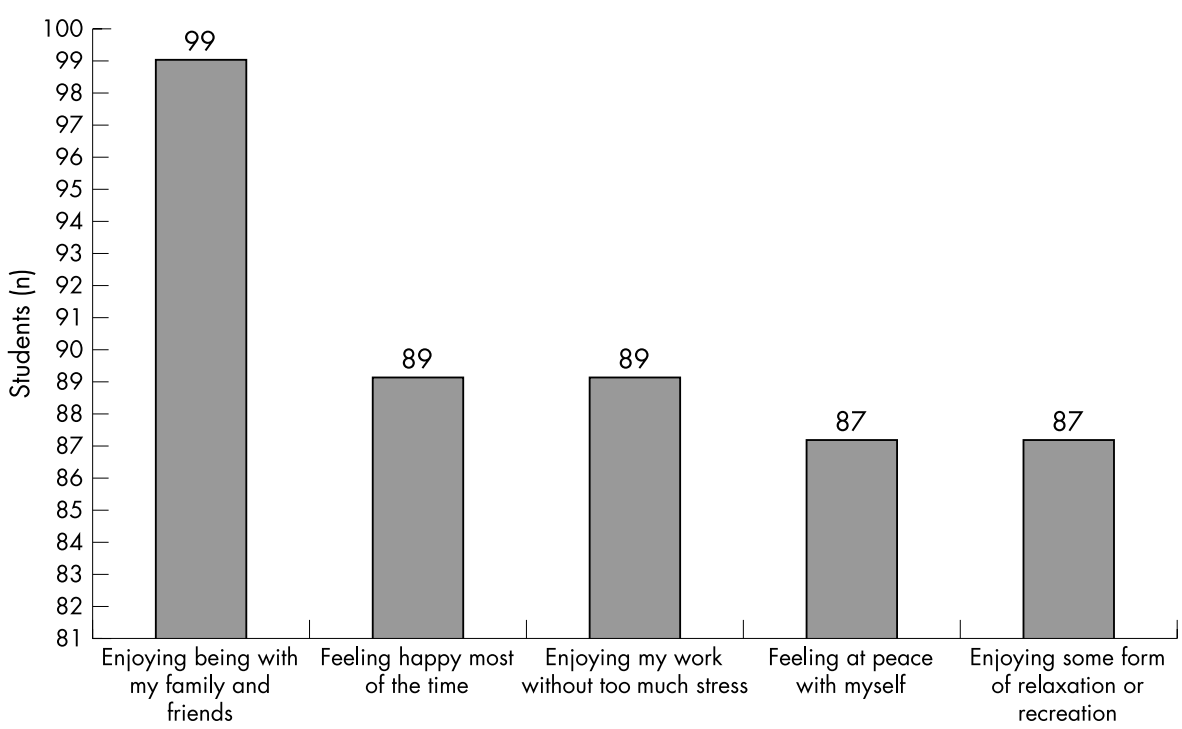

Figure 1 Top five aspects that are perceived to be important to being healthy.

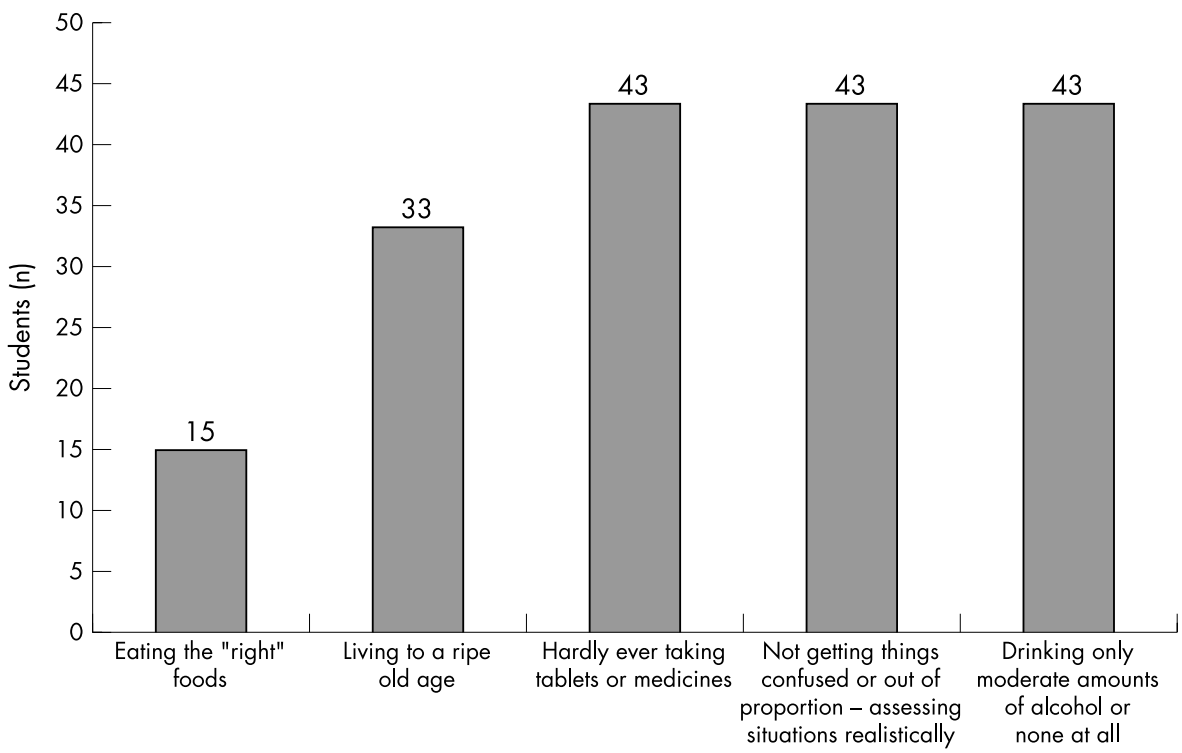

Figure 2 Least five aspects that are perceived to be important to being healthy.

- Nutrition and health

- Smoke free environment

- Balanced diet

- Learning how to choose a healthy diet

- The importance of adequate water intake

\section{PERCEPTION OF HEALTH AFTER TAKING THE COURSE}

After the course, participants received training in concepts of and determinants of health, and they were asked to fill in a questionnaire on their perception of health. The results of what they perceived to be the five most important and the five least important aspects of being healthy are shown in figures 1 and 2. The results indicate that the course participants have moved away from the conventional way of thinking of health as being merely absence of disease, to a more holistic and comprehensive approach to health taking into account psychological and social wellbeing.

\section{CONCLUSION}

Although at this early stage one cannot fully evaluate whether the programme has led to changes in the school curriculum and the organisation of the education system in Hong Kong, or whether it has been successful in achieving the health promoting schools model, it has at least introduced a holistic concept of health promotion into the education system. The projects undertaken by the teachers have inspired and equipped them to move away from more traditional and didactic approaches. The ENHPS project in Poland, the Czech Republic, Bulgaria, and Lithuania has witnessed more relaxed relationships and more opportunities for pupils to engage and be active participants. ${ }^{11}$ Without active involvement of pupils and families in formulating and implementing polices related to health matters, the understanding of the health promoting school concept will be too poor for the schools to be health promoting. ${ }^{12}$ It is therefore important to have a data bank of the health promoting school movements in different parts of the world so that policy makers and administrators can be kept updated. Otherwise the conventional style of didactic 
health education in schools, which cannot enable school children to adopt healthy lifestyles, will continue to be used.

Our programme has put a strong emphasis on training the trainers in a school setting to implement the concept of health promoting schools. Once we have established a pool of trained school health educators, a network of health and education professionals can be formed to promote health at schools. This programme has started the first stage of networking by forming them in to groups for projects supervised by relevant professionals. Networking will improve communication between health services and education staff at all levels, which is essential for the development of the health promoting school concept. ${ }^{13}$ The networking can further facilitate research, publication of health education materials, and dissemination of health information to pupils, other teaching staff and parents. Research is particularly important for assessment and monitoring of the programme. This will increase the movement towards quality health education, as promoted by the European Community Commission on School Health Education. ${ }^{14}$

Based on experiences in different parts of the world the success of health promoting schools must cover a broad range of issues, including community partnership and training of teachers. It should be moving towards more active learning of health related matters. It should also place more emphasise on extra-curricular health promotion activities, improved communication between health and education sectors, active involvement by pupils and parents, and changing policies and practices. $^{15-17}$

The concept of the health promoting school adopts the "bottom up" approach in a very similar way to the new public health, so it will link to broader public health improvement initiatives. ${ }^{18}$ Also, childhood and adolescence are critical periods of learning, growth and development-learning and adopting healthy lifestyles will be a strong determinant for their future health. The improved communication and active involvement of all sectors involved in education will improve the building of a healthy public policy as recommended by the Ottawa Chatter for Health. ${ }^{19}$ A recent report by the World Bank has also emphasised how education and other social investments, such as health, reinforce each other. ${ }^{20}$ Early childhood programmes increase the effectiveness of primary and secondary education, which brings about improved health and increased incomes. These gains then boost productivity and, ultimately, lower the cost of providing basic social services.

The long term outcomes of the programme should therefore tackle boarder objectives. The outcomes should not just be monitored by disease morbidity or mortality. Students' knowledge, attitude, and behaviour with regard to positive health should be measured. Other measures such as partnership and participation in health, curricular and extracurricular activities on health related issues, school policies on health, local and national policies on health, and attitudes of educator towards health education should also be monitored.

With the heavy emphasis on academic achievement and lack of long term planning for the health education curriculum in the present education system in Hong Kong, the objectives would not be easily implemented territory wide. It will involve a lot of changes and lobbying. To strengthen our position, the health and education professionals trained in health promotion and health education must join forces. Therefore a professional association, the Hong Kong Health Education and Health Promotion Foundation, has been established. This nongovernment organisation can represent diverse interests that can advocate in different settings and at all levels of influence, like the Australian Health Promoting School Association..$^{21}$ The Foundation can further improve networking, awareness raising, and try to shape the conceptualisation of a health promoting schools and other aspects of health promotion to accommodate the individual country's specific context. However, all these need to start off with a comprehensive programme to train the trainers and involve partners beyond health sectors so a good network can be established.

\section{ACKNOWLEDGEMENT}

We would like to express our deepest appreciation to the Quality Education Fund of the Hong Kong Special Administrative Region Government for the financial support of the programme; and the Hong Kong Subsidized Secondary Schools Council, Subsidized Primary Schools Council and Hong Kong Special Schools Council for their active participation in the programme. We would like to express our deepest gratitude to the Education Department in providing invaluable advice and recognition to the programme.

\section{Authors' affiliations}

A Lee, Department of Community and Family Medicine, The Chinese University of Hong Kong

C Tsang, Healthy Schools Programme, Hong Kong

S H Lee, School of Public Health, The Chinese University of Hong Kong

C Y To, Department of Education, The Chinese University of Hong Kong

Correspondence to: Dr A Lee, Department of Community and Family Medicine, The Chinese University of Hong Kong, 4th Floor, School of Public Health, Prince of Wales Hospital, Shatin, NT, Hong Kong; alee@cuhk.edu.hk

Accepted for publication 17 February 2002

\section{REFERENCES}

1 Levin LS. The European Health Promoting School in the context of social and economic development. The First Conference of the European Network of Health Promoting Schools, Thessaloniki-Halkidiki, Greece, 1-5 May 1997. (Available from the ENHPS Technical Secretariat of the WHO Europe Regional Office).

2 Booth ML, Samdal O. Health-promoting Schools in Australia: models and measurement. Austr N Z J Public Health 1997;21:365-70.

3 European Network of Health Promoting Schools. Network News. $3 r d$ edn. Copenhagen: European Network of Health Promoting Schools, 1997:1 1-12.

4 St Leger L. Australian teachers' understanding of the health promoting school concept and the implications for the development of school health. Health Promotion International 1998;13:223-35.

5 The Health Promoting School - an investment in education, health and democracy: Case study book. First Conference of the European Network of Health Promoting Schools. Thessaloniki-Halkidiki, Greece, 1-5 May 1997. (Available from the ENHPS Technical Secretariat of the WHO Europe Regional Office.)

6 Rogers E, Moon M, Mullee MA, et al. Developing the 'health-promoting school'-a national survey of healthy schools awards. Public Health 1998; 1 12:37-40.

7 Carpell H, Macdonald S. The School health service in Fife: a survey of the views of school head and guidance teachers. Public Health 1995; 19:319-26.

8 Lee A. Health Promoting School: a new challenge for school teachers. [Letter]. J Public Health Med 1999;21:483-4.

9 Smith C, Roberts C, Nutbeam D, et al. The health promoting school: progress and future challenges in Welsh secondary schools. Health Promotion International 1992; 7:171-9.

10 Rowlong L, Ritchie. Health Promoting Schools: issues and future directions for Australia and the Asia Pacific region. Asia Pac J Public Health 1996-97;9:33-7.

11 Thomas C, Parsons C, Stears D. Implementing the European Network of Health Promoting Schools in Bulgaria, the Czech Republic, Lithuania and Pollard: vision and reality. Health Promotion International 1998; 13:329-38.

12 Thomas M, Benton D, Keirle K, et al. A review of the health promoting status of secondary schools in Wales and England. Health Promotion International 1998;13:121-9.

13 Campell H., Macdonald S. The school health service in Fife: a survey of the views of school head and guidance teachers. Public Health 1995; 109:319-26.

14 William T, Jones $\mathrm{H}$. School health education in the European Community. J Sch Health 1993;63:133-5.

15 Nutbeam D. Promoting health and preventing disease: an international perspective on youth health promotion. J Adolesc Health 1997;20:396-402.

16 Brindis C. Health policy reform and comprehensive school health education: the need for an effective partnership. J Sch Health 1993:63:33-7.

17 WHO. Promoting health through schools. Report of a WHO Expert Committee on Comprehensive School Health Education and Promotion. World Health Organ Rep Ser 1997;870:i-iv; 1-93.

18 Ashton J, Seymour H. The new public health. Oxford: Oxford University Press, 1986.

19 WHO. The Ottawa Charter for Health Promotion. Geneva: WHO, 1986

20 Sandstrom S. Economic reform and investment in people: the keys to development. Address to the World Summit for Social Development. Copenhagen: World Bank Group, 10 March, 1995.

21 Rowling $\mathbf{L}$. The adaptability of the health promoting schools concept: aA case study from Australia. Health Education Research 1996;1 1:519-26. 